\title{
More Basic Research Needed
}

\begin{abstract}
Herwig Schopper, the EPS President, discusses an Opinion on Basic Research in the Next Framework Programme that was sent recently by the EPS Executive Committee to Edith Cresson, the Member of the European Commission responsible for science, research and development.
\end{abstract}

The discovery and exploitation of physical, chemical and biological phenomena have given Europe and other industrialized countries advanced welfare systems combined with a high life expectancy and the ready availability of energy, food, mobility, and leisure time. Owing to today's problems such as unemployment, state deficits and criminality, politicians and the population as a whole often forget that this standard of living was achieved solely by vigorous effort - an effort which was ultimately based on fundamental research, where physics played a major role. Future technological development to maintain our advantages and to cover, in addition, the needs of the developing countries calls for an even greater effort; in view of the long-term aspects, basic research has also to be supported.

The present tendency, however, is to concentrate on near-term economic competitivity so the view is often put forward that research and development should be guided by market needs. Immediate competition might justify such an attitude, but relying on the evolution of existing technologies will not guarantee long-term competitivity. Indeed, the Japanese government has decided to double in the coming five years the funding of research at universities since the country anticipates that new ideas and visions will emerge from basic research.
The difficult question is, of course, a quantitative one: how much of our resources should be used to support basic research ? There is no objective answer to this question, although history has shown that industrialized countries should spend about $10 \%$ of their overall R\&D budget on basic science. A recent report by the Israel Academy of Sciences and Humanities has argued that if a country spends more than $20 \%$ than it has insufficient industry to benefit from what is being accomplished in basic science. Conversely, spending less than $7 \%$ of the total national R\&D budget on basic research means that one has done next to nothing.

The science policy of the European Union (EU) is governed by the subsidiarity principle which implies that the Union's actions should be complementary to national programmes. Indeed, the EU's total spending on R\&D amounts to only a few percent of the combined national efforts of its member states. The major part of the EU Framework Programme

\section{EPS Opinion on Basic Research in the Next Framework Programme}

In the past European Union (EU) Framework programmes have focused on the development of generic technologies. These programmes have recently been supplemented by task forces which can be seen as driven by urgent social concerns. It is to be expected that EU research policy will remain applicationoriented in the future.

However, we want to emphasize the widely recognized role that basic research plays for the long-term development of technology, industry and the economy. To guarantee European competitivity in the long run, this aspect should be taken into account when the next Framework Programme is set up. In particular, knowledge-based industries such as information and communication technology do not fit easily into the main EU programmes, as is well expressed in the European Commission's Green Paper on Innovation. For this reason the research policy needs to be established in a wider context that takes into account basic and applied research.

We do not expect that physics should enjoy privileged treatment, but it should obtain an adequate support if account is taken of its benefits to society in the general understanding of Nature, in applications in technology and medicine, and as the methodological basis for other sciences, e.g. chemistry, biosciences, geosciences. It has also pioneered the introduction of communication networks, new methods of teaching and the use of large facilities. Research networks in physics have been spearheading international cooperation in an outstanding way.

In parallel with other scientific bodies, such as European Science and Technology
Assembly and the European Science Foundation whose recommendations we strongly support, we should like to make some specific suggestions. We believe that the scientific infrastructure in Europe could be strengthened by taking these into account when the fifth Framework Programme is formulated.

\section{Suggestions}

1. The support given to training and mobility has been one of the most successful actions of the EU. Indeed knowledge and skills are best acquired by training in high-level research. The objectives of the ERASMUS and TEMPUS programmes should be continued and strengthened in the fifth Framework Programme. EPS has made a significant contribution to the management of the physics part of ERASMUS and TEMPUS and to the programmes themselves. It is prepared to continue to do so in follow-up programmes.

2. The support of conferences is essential for a better cooperation between EU countries on the one hand, but also with those in central and eastern Europe. Conferences also contribute to better relations between the academic world and industry. The funds for conferences should be increased and the programme should be handled in a more flexible way.

3. Large facilities have proven to provide excellent infrastructure for interdisciplinary research and international cooperation. Although the principle of subsidiarity will limit the EU actions as far as the construction and operation of large facilities is concerned, the present programme for their use should be considerably increased in order to improve the exploitation and coordination of large facil- ities and provide better access for scientists from smaller and less developed countries.

4. Small companies, often developed in the incubator units of university campuses, are - seeds of future growth for European industry;

- ideal interfaces between the academic and commercial world;

- less resistant than larger companies to involvement with EU research programmes. With only a few employees (at least initially) they are the extreme lower end of the conventional "small and medium enterprises" definition. They deserve a special place in European research policy.

Grants to such companies can be small and of an exploratory nature. Every effort should be made to see that they are not burdened by paperwork. Support of this kind is available through structural funds in disadvantaged regions, but it is not always well attuned to the needs of technology-based companies. Moreover, such "microcompanies" can make an important contribution within more developed (but possibly stagnant) economies. The EPS through its Group specializing in industry links, can help to formulate and promote policy on the support of these new enterprises.

\section{Summary}

EPS considers it as its obligation to contribute to the success of the European Union programmes. As in the past, it offers its services, be they in a consultative role or in implementing programmes on behalf of the European Commission. 
concentrates on developing generic technologies at a pre-competitive level, with the topics mainly determined by industrial needs. The programme has recently been complemented by Task Forces which are even more strongly determined by today's needs, namely technology for automobiles, aeroplanes, railways, multimedia, etc.

It was hoped that the Maastricht agreement would make it easier for the Union to extend its activities in a broader way to basic research. Meanwhile, several European scientific bodies (e.g., European Science Foundation, European Union advisory committees, European Science and Technology Assembly) have made recommendations which also imply a strengthening of basic research. However, the preparations for the next Framework Programme do not indicate such a trend. EU policy will of course remain application oriented, but it would be useful if, for instance, each specific programme contained a small component for research relevant to the programme, but not directly related to an objective.

Based on the reactions and worries of some of our members, and on discussions in the Divisions and Interdivisional Groups, the Executive Committee decided to address the appropriate European Commissioner, E. Cresson, and to supplement the recommendations by other organizations with a statement covering a few specific issues. A memorandum (see insert) was formulated and sent in June to research ministers and to the European Parliament.

Secondly, on 1 July an EPS delegation comprising the President, Vice-President, Secretary, and Secretary General met J. Routti who took over as the DirectorGeneral of the European Commission's Directorate-General for Science, Research and Development (DG-XII) at the begin-

\section{Framework Related Documents Available on EurophysNet at http://epswww.epfl.ch}

- Green Paper on Innovation: this European Commission (EC) document set the scene for much of the current discussion on the European Union's 5th Framework Programme for science and technology.

- Preliminary Guidelines for the 5 th Framework Programme "Inventing Tomorrow": a draft proposal by the EC released in August 1996.

- Sth Framework Programme: final programme outline. Due to be released by the EC by the end of 1997.

- ECIndustrial Research and Development Advisory Committee report on the 4th Framework urging more support for basic research.

- Competitive Position of European Science, Technology and Industry: a European Science and Technology Assembly opinion in relation to the 5 th Framework pro-

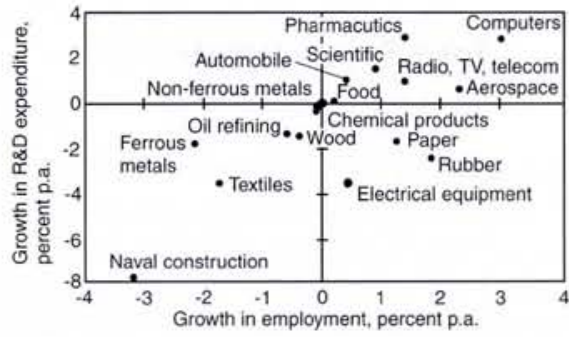

$R \& D$ expenditure correlates with the growth of employment. Average percentage growth rates of employment by industry relative to total manufacturing growth for 13 OECD countries during 1973-90. From the European Commission Green Paper on Innovation, Bulletin of the European Union, Supp. $5 / 95$ (1995).

ning of 1996. The aim was to discuss future policy and possible areas of cooperation with him and his colleagues, notably P. Kind who is responsible for cooperation networks and access to large facilities, and B. Schmitz who is responsible for indicators and accompanying measures. Dr. Routti, a physicist by training, has a full understanding and appreciation of basic research, and an impressive record as the Director of SITRA, the Finnish agency for research and innovation under the direct responsibility of the Finnish Parliament, where he made considerable contributions to the rapid development of Finland's high-tech enterprises. He favours strong basic research but feels, however, that it should also contribute to economic success through an efficient mechanism for transferring technology .

Four of the memorandum's topics were discussed in some detail, together with several general aspects of collaboration. The President pointed out that the ERASMUS, TEMPUS and TMR mobility programmes are very successful and have made considerable contributions to a closer cooperation in Europe. They should be strengthened since at present the suc-

gramme which also urges more support for basic research. - European Parliament 1995 Annual Report on Research and Technological Development Activities in the EU: the first report, as now required under the Maastricht Treaty. In covering the transition year from the 3 rd to 4 th Frameworks,

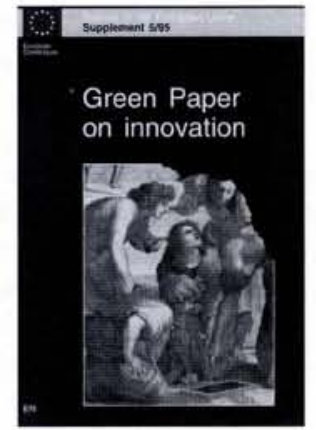
indicates the weaknesses of the current Framework. - European Parliament discussion document on the 5 th Framework: due to be to released in October 1996. - Beyond Framework IV: A European Science Foundation position paper in two parts. cess rate for applications to some TMR activities is a mere $6 \%$, implying that the effort of the majority of the applicants is in vain. Various ways to improve the success rate were considered. The introduction of qualification criteria could improve the situation so rules for qualified applicants will probably be implemented. However, it was agreed that the formulation of suitable criteria is very difficult and insofar as physics is concerned, it was ruled out that certain fields of physics should be exempted. EPS was invited to suggest qualification criteria and it was indicated that physics could possibly be a testing ground for a qualification procedure.

The delegation argued that specific programmes were not appreciated because applicants felt frustrated when applications were unsuccessful. Providing more information and making selection procedures more transparent would probably help improve acceptance by scientists..

We expressed our willingness to continue to help manage certain parts of the mobility programmes, notably student mobility within ERASMUS and TEMPUS, and it was established that DG-XII support of conferences will continue as at present (i.e., for general conferences with a broad impact on science and society; TMR Euroconferences; European Research Conferences; dissemination of information).

We underlined the importance of further support for using and accessing large facilities, which include relatively small installations and not only the very large facilities. Research at these installations provides excellent opportunities, even for small groups, to participate in international and interdisciplinary work and to train scientists and engineers. The Director-General indicated that support for this activity will continue in the new Framework Programme.

Regarding relations between academia and industry, the importance of support for smaller enterprises was discussed, together with other more general issues.

We were assured that the good relations between the Commission and the EPS will continue under the new DirectorGeneral, while those responsible for the various specific programmes will redouble their efforts to help develop European science, and among it physics, in the most efficient and flexible way possible. However, we received the impression that increases in funding for basic research will be very limited, and even unlikely. It seems, moreover, that legal aspects and restrictions are becoming more important. 